Utah State University

DigitalCommons@USU

Mechanical and Aerospace Engineering Student Mechanical and Aerospace Engineering Student Publications and Presentations

$1-4-2021$

\title{
3D-Printed Wings with Morphing Trailing-Edge Technology
}

Benjamin C. Moulton

Utah State University, ben.moulton@usu.edu

Douglas F. Hunsaker

Utah State University, doug.hunsaker@usu.edu

Follow this and additional works at: https://digitalcommons.usu.edu/mae_stures

Part of the Mechanical Engineering Commons

\section{Recommended Citation}

Moulton, B. C., and Hunsaker, D. F., "3D-Printed Wings with Morphing Trailing-Edge Technology," AIAA Scitech Forum Virtual Event, January 2021, AIAA-2021-0351 DOI: 10.2514/6.2021-0351

This Conference Paper is brought to you for free and open access by the Mechanical and Aerospace Engineering Student Research at DigitalCommons@USU.

It has been accepted for inclusion in Mechanical and Aerospace Engineering Student Publications and Presentations by an authorized administrator of DigitalCommons@USU. For more information, please contactdigitalcommons@usu.edu.

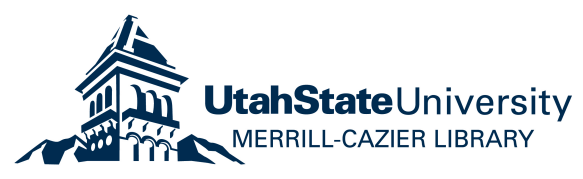




\title{
3D-Printed Wings with Morphing Trailing-Edge Technology
}

\author{
Benjamin C. Moulton* and Douglas F. Hunsaker ${ }^{\dagger}$ \\ Utah State University, Logan, Utah 84322-4130
}

\begin{abstract}
In recent years, various groups have attempted to improve aircraft efficiency using wings with morphing trailing-edge technology. Most of these solutions are difficult to manufacture or have limited morphing capability. The present paper outlines a research effort to develop an easy to manufacture, fully 3D-printed morphing wing. This approach is advantageous due to the low cost, minimal man-hours required for manufacturing, and speed at which design iterations can be explored. Several prototypes were designed and tested and lessons learned from these iterations have been documented. Additionally, printer settings have been tested and catalogued to assist others attempting to reproduce these results. Performance was considered in terms of total deflection. Two concepts are presented as potential 3D-printed morphing-wing mechanisms. The Airfoil Recambering Compliant System (ARCS) is presented as a solution for a wing using continuous trailing-edge technology. The Kinetic Internal Nexus Compliant System (KINCS) is presented as a solution for a wing using discontinuous trailingedge technology. The final KINCS design used for a prototype flying-wing aircraft is presented.
\end{abstract}

\section{Nomenclature}

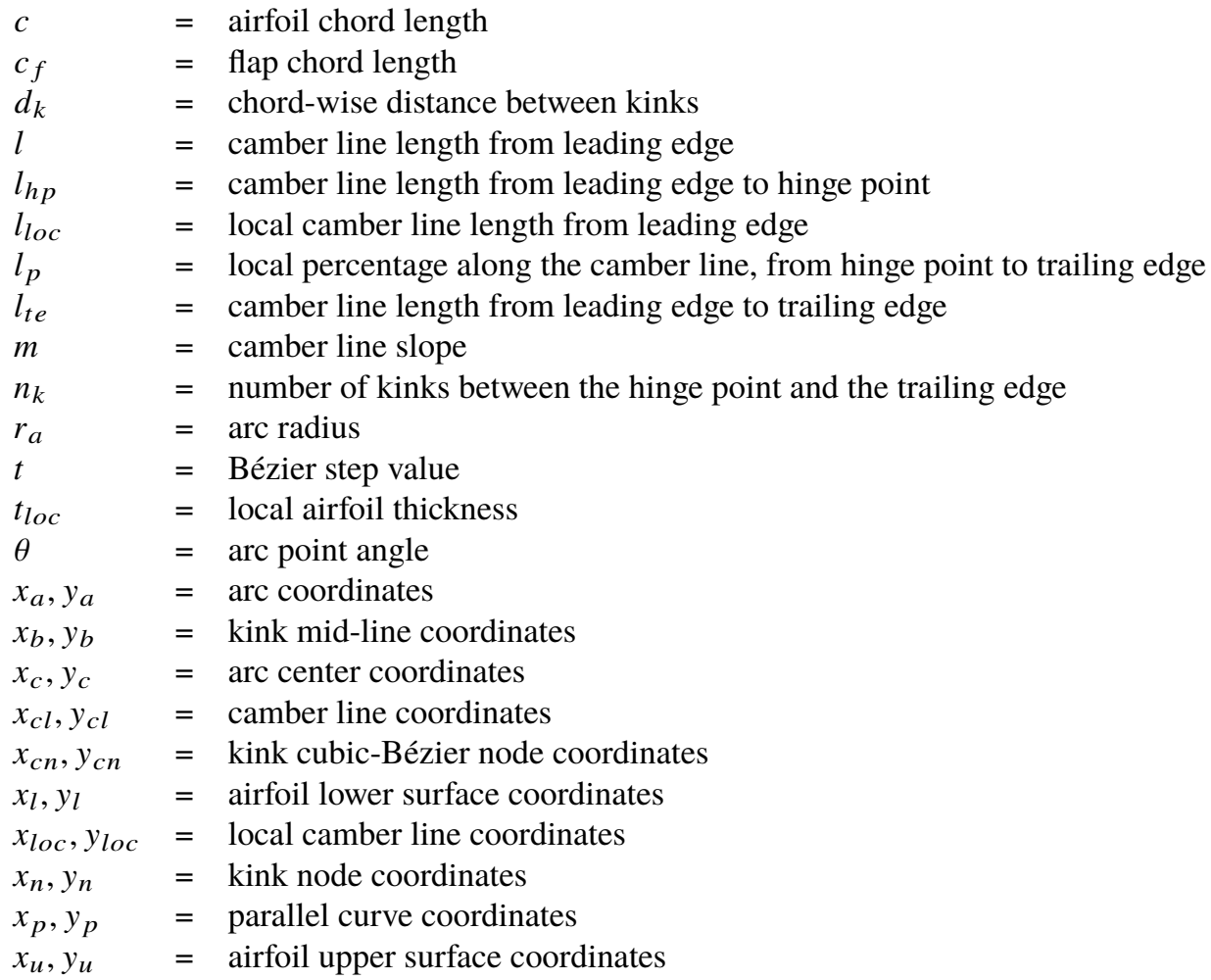

\footnotetext{
*Graduate Research Assistant, Mechanical and Aerospace Engineering, 4130 Old Main Hill, AIAA Student Member

${ }^{\dagger}$ Assistant Professor, Mechanical and Aerospace Engineering, 4130 Old Main Hill, AIAA Senior Member
} 


\section{Introduction}

$\mathrm{M}$ ORPHING aircraft have the capability to control aerodynamic forces and moments during flight more efficiently than traditional aircraft. Some designs accomplish this through continuous control-surface deflections such as variable-camber trailing edges or parabolic flaps with sufficient elasticity so that the trailing edge can be continuous. The Wright brothers used wing warping to control their aircraft. This control method was generally omitted from later aircraft designs in order to simplify the manufacturing process. With modern manufacturing methods, recent research has examined how morphing control-surfaces can be developed for use in current aircraft designs. For example, the Air Force Research Laboratory developed the Variable-Camber Compliant Wing (VCCW) [1], NASA has developed the Variable-Camber Compliant Trailing Edge (VCCTE) [2], and a joint effort resulted in the design of the Flexsys aircraft [3]. Some groups have examined the use of piezoelectrics as actuation mechanisms for morphing-wing aircraft [4], and some have used corrugated internal compliant-structures to induce wing morphing [4, 5]. Morphing wings have also been studied for use on helicopters through the SABRE [6] program using the Fish Bone Active Camber (FishBAC) [7] structure.

Although each of these programs has taken a slightly different approach, they have each impacted the direction of the current research. For example, the FishBAC concept consists of a 3D printed bio-inspired airfoil geometry, where a servo is positioned to deflect the trailing edge via a pulley. The skin of this wing design consists of a pre-tensioned elastomeric sheet adhered to the 3D printed wing surface. For the ARCS design we also approached the challenge by employing 3D printing techniques with elastomeric structures.

One difficulty in developing such a complex mechanism lies in the need for rapid prototyping of the morphing control-surface in order to evaluate the performance of various designs. Additive manufacturing is frequently used where rapid prototyping is required. Fused Deposition Modeling (FDM) is a sub-branch of additive manufacturing which consists of layering melted plastic in discretized sections to form a three dimensional object. Recent studies have used FDM to develop flexible and/or morphing wings [8-12]. Such designs have been successful in demonstrating viable solutions to morphing flight using FDM. There are several advantages to using FDM for this process, as outlined here.

First, FDM is repeatable. The machine will repeat the manufacturing process exactly as detailed in the model GCODE file. The removal of human error from the process allows for the model to be reprinted with minimal variation. Minor details in a model can be modified and manufactured with confidence that the resulting product will have been made in the same manner as the baseline model.

Second, compared to manual manufacturing processes, FDM is highly replicable. Given the slicer print settings for a model, a separate FDM 3D printer may achieve the same results as the original printer. As the process is repeatable, the results can be verified with confidence by an alternate individual. Replicability removes the manufacturing nuances of the fabricator.

Third, whereas a test system's destruction would cause significant delays due to manufacturing time, FDM allows for a test system to be reconstructed more quickly than traditional manufacturing and assembly methods. The rapid prototyping allows for small changes inspired by a test to be quickly manufactured and analyzed. With FDM, a small replaceable piece may be designed for a modular system. A model generally prints within hours versus the days and weeks required to fabricate the same prototype using a different manufacturing method. This allows for design changes to be explored quickly.

Fourth, the materials for FDM are generally cost effective. Along with the rapid prototyping, the cost decrease allows for several prototypes and testing platforms to be manufactured. The decreased cost also allows one to test various circumstances and designs knowing that the test bed's destruction will not cause significant financial difficulty.

Finally, the materials for FDM are relatively durable. Even simple FDM materials such as polylactic acid (PLA) can be used to fabricate a sturdy aircraft structure. For example, an FDM radio-controlled aircraft can be landed without landing gear, a boon for weight management.

The purpose of this research is to develop a 3D printed morphing aircraft utilizing the benefits of FDM. This airframe will be tested to demonstrate proverse yaw and yaw control. While several groups have examined morphing wings, few of these designs have been fully 3D printed. Most rely on aluminum test frames or composite manufacturing and significantly long assembly procedures. A fully 3D printed wing's assembly requires little to no assembly prior to use. This significantly decreases the time and complexity of fabrication.

The present paper provides an overview of the design process of this 3D-printed morphing wing mechanism. A description of the internal geometry, which can be applied an arbitrary airfoil, is provided, printer settings and materials are explained, and the resulting characteristics and performance of several designs are considered. Lessons learned are catalogued and the final design is described in detail. The purpose of the paper is to add a solution for low-cost 
manufacturing of 3D-printed designs to the body of work on morphing aircraft, and to provide a discussion of the advantages and disadvantages of various designs.

\section{Morphing Airfoils}

One solution to demonstrate yaw control and yaw authority on a flying wing is to create variable induced and parasitic drag along the wing. This can be done by creating a morphing-airfoil geometry. A morphing airfoil is a two-dimensional airfoil design which is cable of changing its shape due to some input. In the case of a morphing airfoil for a Radio Controlled (RC) aircraft, the input is a digital servo motor. Using the input actuation from this servo motor, the preferable morphing-airfoil must have an efficient flap. The design and manufacturing process must be similarly effective.

\section{A. Articulated and Conformal Control Surfaces}

A parabolic flap deflects with the camber line conforming to a curved parabolic shape, rather than the single-joint articulation of a traditional flap. Studies have geometrically defined and examined the aerodynamic performance of a parabolic flap [13]. The geometries for a deflected articulated flap and deflected parabolic flap on a NACA 2412 airfoil are shown in Fig. 1 .

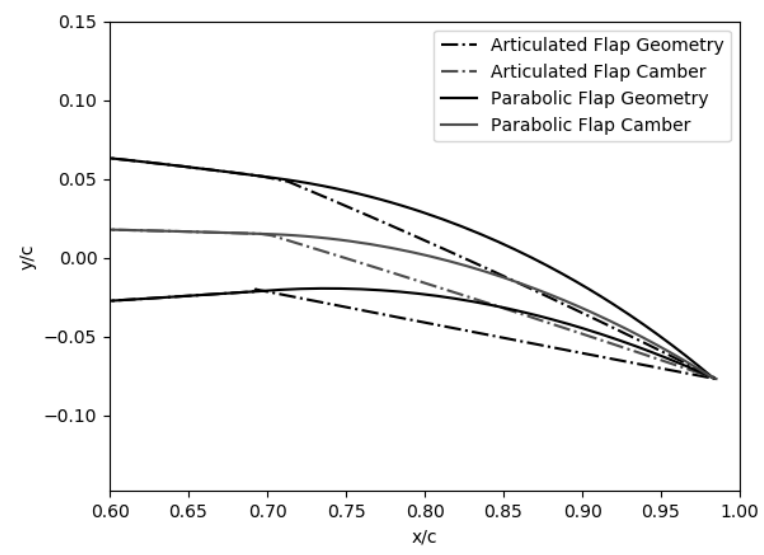

Fig. 1 Geometries of a parabolic and a articulated flap on a NACA 2412 airfoil, with $c_{f} / c=0.3$.

The discontinuity in the camber line slope as shown in Fig. 2 demonstrates an inefficiency of the articulated flap. This inefficiency stems in part from an adverse pressure gradient created on this articulated flap. This adverse pressure gradient causes the flow to separate earlier along the surface of the wing compared to a parabolic flap. This causes the parabolic flap to produce less drag with changes in lift [13]. 


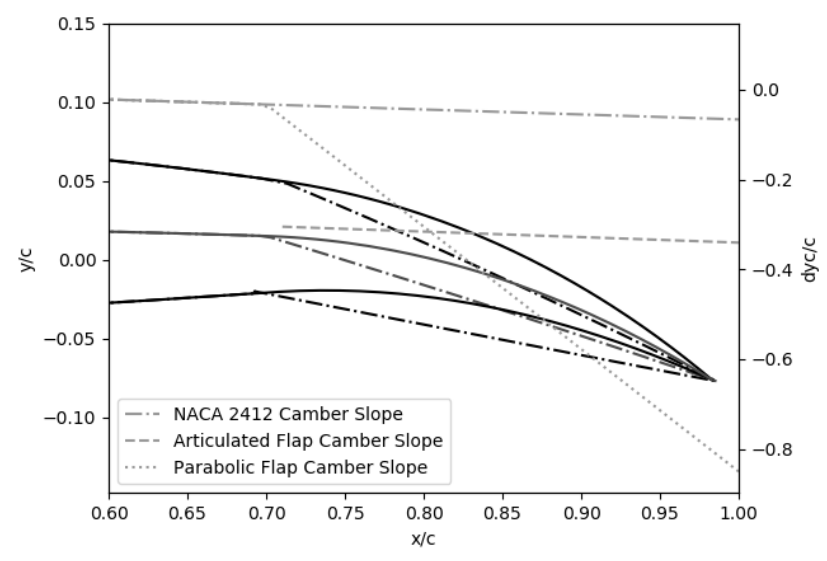

Fig. 2 Camber line slopes of parabolic and articulated flap geometries.

Another benefit to the parabolic flap can be shown in the flap effectiveness. The ideal section flap effectiveness can be calculated for articulated and parabolic flaps using thin-airfoil theory [13]. This effectiveness is defined as the change in zero lift angle of attack resultant from a change in flap deflection. The effectiveness for a NACA 2412 airfoil with articulated and parabolic flap deflection is shown below in Fig. 3 .

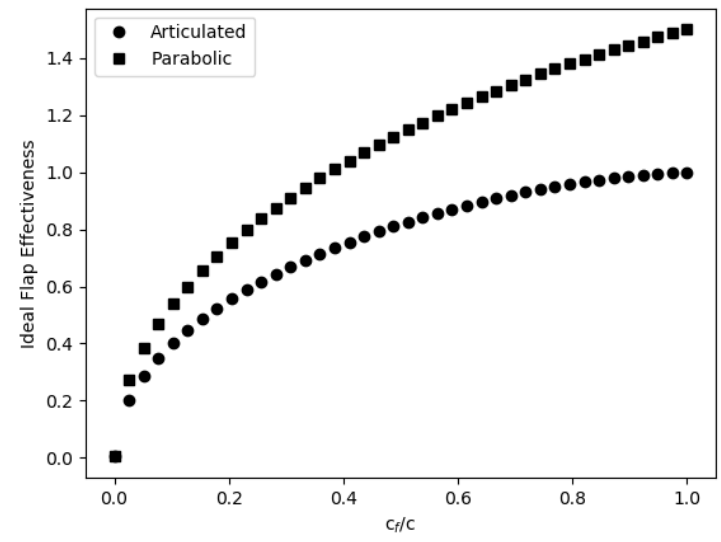

Fig. 3 Ideal section flap effectiveness of parabolic and articulated flaps on a NACA 2412 airfoil.

As seen in Fig. 3. A parabolic flap is more efficient in deflecting the freestream flow than a articulated flap of similar flap chord fraction. Due to the decrease in drag and increased flap effectiveness, the parabolic flap was chosen as the airfoil deflection method. In order to achieve a truly parabolic flap, the airfoil geometry must be constructed so the aft portion of the airfoil can continuously morph. This can be done by making the aft portion of the airfoil a compliant mechanism. A compliant mechanism is a structure which is inherently flexible and strong, able to deform and revert with a negligible loss in structural integrity [14].

\section{B. Manufacturing Technique Decision}

Several manufacturing processes were examined and tested before the wing design process began. Initially, such materials as memory foam, compliant pinewood ribs and carbon-fiber spars were used to create morphing wing prototypes. However, the salient difficulty lies in the unrepeatability of the process, as well as the time taken to manufacture. Due to these difficulties, FDM was investigated as a potential solution. Several non-FDM manufactured prototypes were successful in demonstrating morphing characteristics. These included creating the wing out of Expanded 
PolyStyrene (EPS), memory foam, Ethylene-Vinyl Acetate (EVA), and Expanded PolyEthylene (EPE). The wings were manufactured using laser-cut wooden ribs at the actuation locations. However, the manufacturing time did not justify the success. The weight of the more successful prototypes also dissuaded further study of these concepts.

Three aspects critical to the design and manufacturing process were determined to mitigate the manufacturing problem. Each potential design and its manufacturing process were judged on these three critical aspects. First, the manufacturing process was judged on its feasibility. This required the design to be manufacturable using the services and equipment available at Utah State University. Second, the design was judged on compliance. The wing design must be capable of the deflection needed to demonstrate proverse yaw and yaw control. Third, the manufacturing process was judged on cost. The cost of materials and equipment, as well as the time required for fabrication, and the difficulty of fabrication were used to determine the best process. This manufacturing process was iteratively examined throughout the prototyping process. The process eventually resulted in FDM being the most rapid and reliable method for creating a wing-morphing geometry. The several FDM geometries tested are as follows:

\section{Trailing-Edge Gap}

The trailing-edge gap geometry was designed to examine FDM printed morphing airfoils. This morphing airfoil geometry is shown in Fig. 4. Shown in the figure are the compliant rib (above) and outer skin (below). The compliant portion of the rib was created from parallel offsets to a set of Bézier curves.

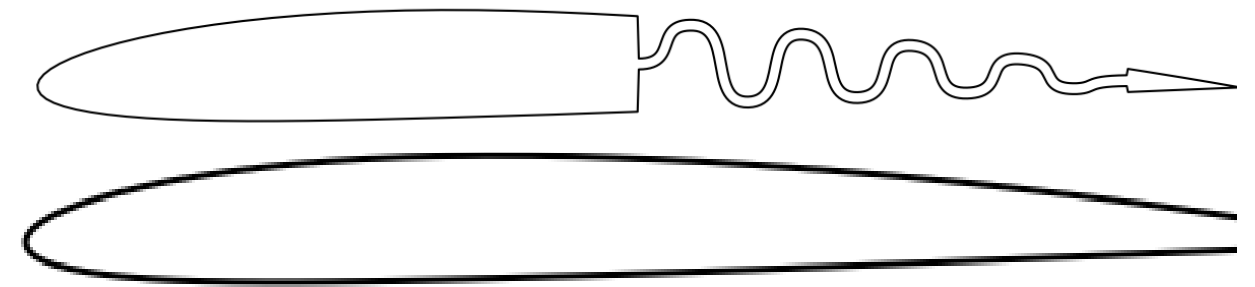

Fig. 4 Trailing-edge gap geometry in a NACA 2409 airfoil, with $c_{f} / c=0.5$.

The compliant rib is connected to the inside of the upper and lower surfaces of the outer skin. The rib is allowed to slide along both surfaces, thus creating a morphing aft portion of the airfoil, with the trailing-edge disconnected. Similar morphing mechanisms has been studied before [15]. The rib remained fixed span-wise as well as connected to each surface. This was done by FDM printing runners span-wise on the peaks and valleys of the compliant portion of the rib. These would slide longitudinally in troughs inside the outer skin during actuation. The section was actuated in one of two ways. One used a servo with a control rod connected to the trailing edge of the compliant rib. The second used a servo with wires connected through the compliant rib upper and lower peaks, similar to other group's designs [5].

Using the wire actuation concept made the actuation mechanism fully internal, a significant benefit. While initial outer skin prints were too thick, the thickness could be decreased to allow for sufficient morphing deflection. The design is also lightweight due to the low density of PLA within the model. However, this design has significant drawbacks. With FDM as the manufacturing method of choice, printing the holes for the wire was difficult due to the relative thickness of the compliant section of the rib. Similarly, the runners on the rib and the troughs inside the skin were difficult to create using FDM.

This design was not chosen due to the difficulty in ensuring the rib remained fixed span-wise, as well as that of running the wire through holes in the compliant portion of the rib. Also, the assembly time after printing was significant enough to dissuade further study of this concept. This design difficulty motivated the desire for an all-inclusive morphing mechanism.

\section{Fish Bone}

The fish bone geometry was designed to be a single FDM print morphing airfoil, and can be seen in Fig. 5 . The structure is printed as a single piece, with the aft outer surface gaps printed large enough to allow deflection and prevent the skin being combined during printing. 


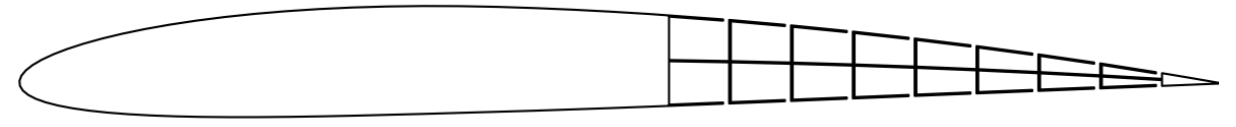

Fig. 5 Fish bone geometry in a NACA 2409 airfoil, with $c_{f} / c=0.45$.

As seen above, significant influence came from the FishBAC design [7]. A flexible pre-tensioned outer skin was adhered to the outer surface on the aft portion of the airfoil. This skin allowed for the airfoil to morph without buckling or bowing in the skin surface. This design is actuated similarly to the FishBAC design [7]. A servo controls a pulley attached to the trailing edge. This pulley runs through the aft vertical fins of the design. Another actuation method uses a control rod attached to the trailing edge, powered by a servo motor in the leading edge of the airfoil.

This design is able to morph parabolically. This is due to the compliance centered on the camber line of the morphing airfoil. The design is also lightweight, and extremely flexible. Another benefit came from a prototype being printed out of a flexible material such as Thermoplastic Polyurethane (TPU). The flexible material allowed for a transverse gradient along the trailing edge, to be discussed later. However, the flexible pre-tensioned skin caused significant difficulty. Assembling this skin added undesirable time to the assembly process. The actuation method similarly added undesirable time to the assembly process.

This design was not chosen due to the difficulty in assembly of adhering a flexible pre-tensioned skin to the outer aft surface of the wing. The design also had significant assembly difficulty with the actuation method. The skin drawback motivated a design in which the skin is included in the morphing actuation.

\section{E. Slip Joint and Semicircles}

The slip joint and semicircles geometry was designed to include a morphing skin, and is shown in Fig. 6 The black outer lines on the figure indicate the wholly PLA-printed portion of the airfoil. The blue outer lines indicate the portion of the airfoil which is printed span-wise in layers of PLA and TPU. This layering method, as seen in Fig. 12, will be discussed in the following morphing-wing section.

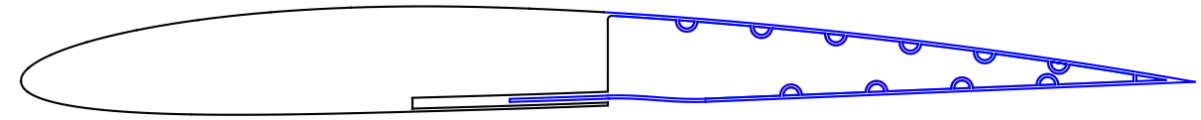

Fig. 6 Slip joint and semicircles geometry in a NACA 2409 airfoil, with $c_{f} / c=0.5$.

This geometry is morphed by sliding a tongue inside a slip joint on the lower surface of the airfoil. Such slip joint mechanisms have been used before in FDM morphing wings [10]. Due to the connection between the upper and lower surface at the trailing edge, sliding the tongue effectively deflects the aft portion of the airfoil. The semicircles on the inside of the aft portion provide support for the upper and lower surfaces during printing, preventing the skin buckling due to heat deformation during FDM. These semicircles do not affect the morphing mechanism in any significant way. It should be noted that the slip joint tongue geometry was created using a Bézier curve between the airfoil skin and an inner parallel-offset airfoil.

This design is extremely simple and lightweight, while providing the morphing capability desired in the final design. This design's skin is able to deflect without the difficulty of post-printing assembly. The mechanism is simply actuated via a servo and control rod connected to the tongue of the morphing portion. With the semicircles in the aft inner of the wing, the printed skin does not have significant heat-deformed buckling. However, due to the absence of connections between the upper and lower surfaces prior to the trailing edge, this design does not morph parabolically. Due to the single connection at the trailing edge, the design morphs with greater bowing on the upper surface and lesser bowing on the lower surface than desirable. This is caused by lack of conformity of the camber line to a parabolic shape during deflection. This also causes the local thickness to change during deflection, another significant drawback.

Another problem can be seen in the corner of the groove as shown in Fig. 6 . This corner trips the flow, transitioning the flow to turbulent earlier along the chord than would otherwise occur. However, this corner was left on the lower 
surface as it was preferable to trip the flow on the lower rather than the upper surface. This is because tripping the flow on the lower surface is less likely to affect the lift generated by the airfoil.

This design was not chosen due to the inability to fully conform the camber line as required by a parabolic flap. This failure motivated a modification of this design where the upper and lower surfaces are connected to create parabolic deflection. Such a design would also need to maintain the local thickness of the airfoil.

\section{F. Airfoil Recambering Compliant System (ARCS)}

The ARCS geometry was designed to conform the camber line as required for a parabolic flap, and can be seen in Fig. 7. The black outer lines indicate the portion of the airfoil which is printed using PLA, and the green outer lines indicate that which is printed using TPU. The blue lines indicate the portion of the airfoil which is printed in span-wise layers of PLA and TPU. This layering method, as seen in Fig. 13, will be discussed in the following morphing-wing section.

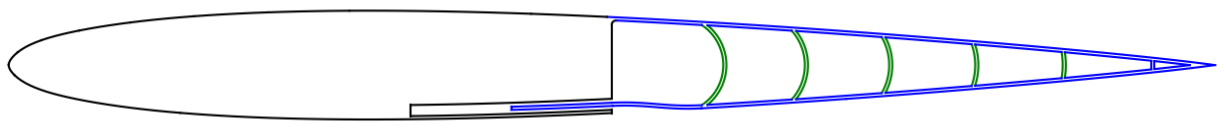

Fig. 7 ARCS geometry in a NACA 0009 airfoil, with $c_{f} / c=0.5$.

The actuation occurs on the tongue on the lower surface of the airfoil. As the tongue slides within the groove, the upper and lower surfaces deflect parabolically due to the connecting arcs between the upper and lower surfaces. These TPU arcs are more flexible than the composite flexibility of the upper and lower morphing surfaces. This flexibility contributes to the aft portion parabolic deflection while maintaining the local thickness. The arcs radius is configured larger when closer to the trailing edge of the airfoil. Thus, the arcs closer to the hinge point will move further than those closer to the trailing edge. This causes the change in the camber-line angle to be greater near the hinge point and lesser near the trailing edge. It should be noted that the geometry forward of the hinge point has no bearing on the wing morphing mechanism, and simply provides structural support.

The geometry for these arcs is determined mathematically from the camber line. The arcs are equally spaced along the camber line between the hinge point and a set point near the trailing edge of the airfoil. The local slope of the camber line is used to determine where the normal to this point intersects the upper and lower surfaces of the airfoil. These points are used to determine the local thickness as shown in

$$
t_{l o c}=\frac{\sqrt{\left(x_{u}-x_{l}\right)^{2}+\left(y_{u}-y_{l}\right)^{2}}}{2}
$$

The local camber line length can then be determined from the camber line points as

$$
l_{l o c}=\sum_{x_{c l}=0}^{x_{c l}=x_{l o c}} \sqrt{\left(x_{i+1}-x_{i}\right)^{2}+\left(y_{i+1}-y_{i}\right)^{2}}
$$

after which the local arc radius can be found as the product of the local thickness and a ratio based on the local camber line length. This ratio begins as unity at the hinge point and extends to infinity at the set end point near the trailing edge. This forces the arc geometry to begin as a semicircular arc at the hinge point, and increasingly becomes a constraining vertical connection between the upper and lower surfaces of the airfoil. This is done to encourage the actuation to occur closer to the hinge point than the trailing edge. This arc radius is calculated as

$$
r_{a}=t_{l o c} \frac{l_{t e}-l_{h p}}{l_{t e}-l_{l o c}}
$$

The center of this arc can be determined from the upper and lower surface points through which it passes and the arc's radius. The arc center is calculated as

$$
x_{1}=x_{m}-d_{y} \frac{d}{q} \quad, \quad y_{1}=y_{m}+d_{x} \frac{d}{q} \quad, \quad x_{2}=x_{m}+d_{y} \frac{d}{q} \quad, \quad y_{2}=y_{m}-d_{x} \frac{d}{q}
$$


where

$$
\begin{gathered}
x_{m}=\frac{x_{u}+x_{l}}{2}, \quad y_{m}=\frac{y_{u}+y_{l}}{2} \\
d_{x}=x_{l}-x_{u}, \quad d_{y}=y_{l}-y_{u} \\
q=\sqrt{d_{x}^{2}+d_{y}^{2}}, \quad d=\sqrt{r_{a}^{2}-\left(\frac{q}{2}\right)^{2}}
\end{gathered}
$$

It should be noted there are two solutions to this method, $\left(x_{1}, y_{1}\right)$ and $\left(x_{2}, y_{2}\right)$. The correct solution is that in which the $x$ coordinate is closer to the leading edge of the airfoil than either the upper or lower surface $x$ coordinates.

Here the user can determine the top and bottom arc angles, where the arc intersects an inner offset of the airfoil surface. The arc geometry can then be found as

$$
\begin{aligned}
& x_{a}=r_{a} \cos \theta+x_{c} \\
& y_{a}=r_{a} \sin \theta+y_{c}
\end{aligned}
$$

With the arc radius and center known, the arc thickness can be added to the radius. Using this new radius with new intersection angles for the new arc and inner offset airfoil surface, the new arc geometry can be found as in Eq. (5) and 66. For further study of the ARCS geometry, the reader can retrieve the code used to create this geometry

The geometric definition of a parabolic flap [13] may be used to examine the parabolic deflection of any geometry. Examples of the ARCS geometry deflected parabolically are shown in Fig. 8 .

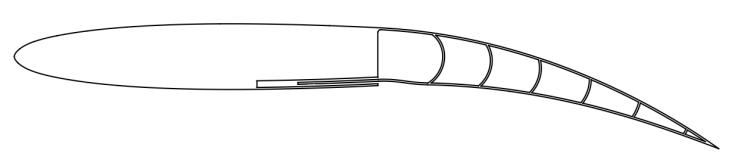

(a) $+15^{\circ}$ Deflection

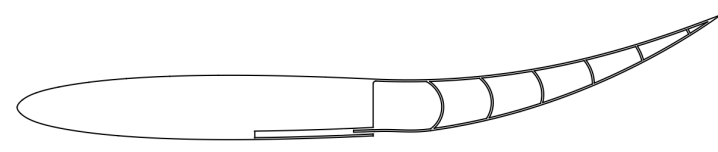

(b) $-15^{\circ}$ Deflection

Fig. 8 ARCS geometry in a NACA 0009 deflected parabolically, with $c_{f} / c=0.5$.

This design is able to deflect with a parabolic shape while maintaining local thickness. For this lightweight design, little to no assembly is required excepting servo insertion. This decrease in assembly time is due to the simplicity of the design. However, this design is difficult to print. This difficulty is inevitable with multi-material and TPU FDM printing. The TPU used in this case, NinjaFlex TM ${ }^{\mathrm{T}}$ is extremely elastic. FDM printing with this material will be discussed in a later section. While use of this material is a significant boon to the deflection, it significantly increases print time and complexity.

It should be noted that the ARCS design is fully proficient at creating a parabolic morphing airfoil. Due to study results on a morphing wing discussed in the following section, and the multi-material requirements of this design, it was not chosen for the final morphing design. The multi-material characteristic motivated the design of a mono-material morphing airfoil.

\section{G. Kinetic Internal Nexus Compliant System (KINCS)}

The KINCS geometry was designed to be FDM printed from a single material, and is shown in Fig. 9 Preliminary prototypes were laser cut out of birch wood 3-ply sheets. These morphing airfoils were stacked onto a spar and connected together at the slip joint tip and trailing edge to ensure continuous deflection across the wing. Due to the success of this design in assimilating the geometry to a parabolic flap, it was considered as a separate potential design, and FDM printed.

\footnotetext{
*https://github.com/benjaminmoulton/ARCSgeometry

${ }^{\dagger}$ NinjaFlex ${ }^{\mathrm{TM}}$ is owned by NinjaTek, a Fenner Drives, inc. brand
} 


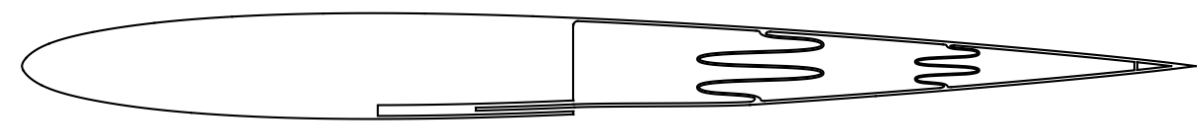

Fig. 9 KINCS geometry in a NACA 0009 airfoil, with $c_{f} / c=0.55$.

The kinks connecting the upper and lower surface function similarly to the arcs in the ARCS design. The kinks provide elastic connections which constrain deflections to conform the camber line to a parabolic shape, while maintaining local thickness. The kinks provide the requisite compression and tension for the morphing airfoil to deflect parabolically. Actuation is powered by a servo placed in the leading edge of the airfoil. The servo is connected to the tongue via a control rod.

The geometry is created for each kink as follows. The nodal local camber-line percentage of the morphing portion of the airfoil is found using Eq. (2) as

$$
l_{p}=\frac{l_{l o c}-l_{h p}}{l_{t e}-l h p}
$$

The nodes of the kink are initialized as a line which connects the inner upper and lower surfaces of the geometry as

$$
\begin{array}{cc}
x_{n i} \in x_{n}=x_{u}-i \frac{x_{u}-x_{l}}{n_{k}}, & 0 \leq i \leq n_{k} \\
y_{n_{i}} \in y_{n}=y_{u}-i \frac{y_{u}-y_{l}}{n_{k}}, & 0 \leq i \leq n_{k}
\end{array}
$$

where $i$ is an integer. The node points are then shifted in the $\mathrm{x}$ direction to create the kink nodes

$$
x_{n}=\begin{array}{ll}
x_{n i}=x_{n i}-\frac{1}{2} d_{k} l_{p} & , \quad 1 \leq i \leq n_{k}+1 \\
x_{n i}=x_{n i}-\frac{1}{2} d_{k} l_{p} & , \quad 1 \leq i \leq n_{k}+1
\end{array}
$$

These node points are then used to determine the cubic-nodal points required for a cubic Bézier curve. These points are defined as

$$
\begin{gathered}
x_{c n}=\left[x_{n i}, x_{n i}, x_{n i+1}, x_{n i+1}\right] \\
y_{c n}=\left[y_{n i}, \frac{y_{n_{i}}+3 y_{n_{i+1}}}{4}, \frac{3 y_{n_{i}}+y_{n_{i+1}}}{4}, y_{n_{i+1}}\right]
\end{gathered}
$$

The cubic-nodal points are used to define the kink center Bézier curve as

$$
\begin{array}{ll}
x_{b}=(1-t)^{3} x_{c n_{0}}+3(1-t)^{2} t x_{c n_{1}}+3(1-t) t^{2} x_{c n_{2}}+t^{3} x_{c n_{3}}, & 0 \leq t \leq 1 \\
y_{b}=(1-t)^{3} y_{c n_{0}}+3(1-t)^{2} t y_{c n_{1}}+3(1-t) t^{2} y_{c n_{2}}+t^{3} y_{c n_{3}}, & 0 \leq t \leq 1
\end{array}
$$

All the Bézier curves are appended to form a single line, from which points are generated two parallel curves as

$$
\begin{aligned}
& x_{p_{i}}=\frac{x_{b_{i}}+x_{b_{i+1}}}{2}-\frac{d\left(x_{b_{i+1}}-x_{b_{i}}\right)}{\sqrt{\left(x_{b_{i}}-x_{b_{i+1}}\right)^{2}+\left(y_{b_{i}}-y_{b_{i+1}}\right)^{2}}} \\
& y_{p_{i}}=\frac{y_{b_{i}}+y_{b_{i+1}}}{2}+\frac{d\left(y_{b_{i+1}}-y_{b_{i}}\right)}{\sqrt{\left(x_{b_{i}}-x_{b_{i+1}}\right)^{2}+\left(y_{b_{i}}-y_{b_{i+1}}\right)^{2}}}
\end{aligned}
$$


The $d$ value is used to offset the curve by a predefined half-thickness. Fillets are added where the kink meets the upper and lower surfaces to remove stress concentrations. For further study of the KINCS geometry, the reader can retrieve the code used to create this geometry

The parabolic deflection of this morphing airfoil can be determined using the definition of a parabolic flap [13]. Examples of the KINCS geometry deflected parabolically are shown in Fig. 10

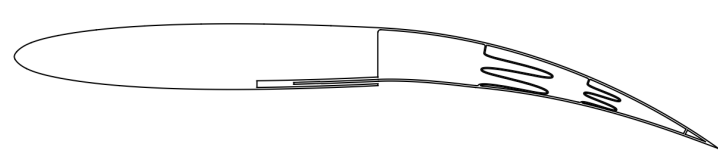

(a) $+15^{\circ}$ Deflection

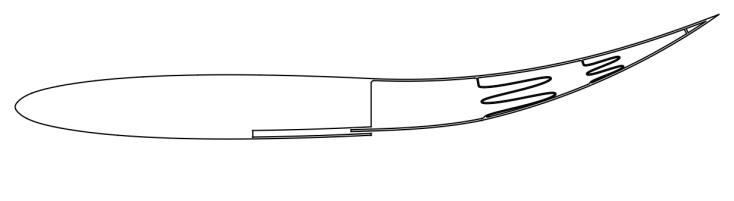

(b) $-15^{\circ}$ Deflection

Fig. 10 KINCS geometry in a NACA 0009 deflected parabolically, with $c_{f} / c=0.5$.

The KINCS geometry is able to conform the camber line to deflect parabolically. The design has the added benefit of being FDM printed from a single material, thus removing the need for difficult and time-costly bi-material 3D printing. This design is simple and incredibly easy to print. Due to the decrease in the number of upper to lower surface-connections required, there is also a decrease in weight for this design. Printing this geometry out of one material frees the second printhead on a dual-extruder printer to print symmetrically to the first head. With the decrease in complexity, and ability to morph the airfoil using a mono-material FDM print, this design was chosen for the final mechanism.

\section{H. Airfoil Selection}

Several airfoils were considered for use with the morphing mechanisms mentioned previously. The Eppler 335 airfoil was examined due to the airfoil's reflexed trailing-edge. An airfoil with a reflexed trailing-edge is used on flying wings because it creates a positive pitching moment about the aerodynamic center of the wing [16]. A later prototype examined the same Eppler 335 airfoil with the thickness as 50\% that of the original thickness. This thinner prototype demonstrated a thinner airfoil could deflect further with the same actuation distance as a prototype using a thicker airfoil. This is caused by the decrease in the thickness distribution's ability to dampen out the deflection from the slip joint actuation. As the airfoil surface is closer to the camber line, the same actuation length on the lower surface results in a greater translation of the trailing edge. The study of this airfoil was discontinued due to the ability with a parabolic flap to artificially create a reflexed trailing-edge.

Thinner airfoils such as the NACA 0006 and AS6903 [17] were also examined. These airfoils were used due to the thinness requisite for the deflection on a continuous control-surface as described in the following morphing-wing section. The NACA 0006 airfoil had the added benefit of being a symmetric airfoil, providing a test bed for the proof of concept of a parabolic flap creating lift at zero angle of attack. The study of these airfoils was discontinued in favor of an airfoil which produces lift at lower angles of attack.

The NACA 2412 airfoil was also examined due to the airfoil's generation of lift at small angles of attack. Due to the morphing wing design change discussed in the following morphing-wing section, and to allow room for servo-mechanisms, the NACA 2412 airfoil was chosen for the final morphing geometry. This airfoil has provided the necessary thickness for the servo-mechanisms, as well as the camber to produce lift at low angles of attack. For this reason, this airfoil is to be used in the final morphing geometry design.

\section{Morphing Wings}

A morphing wing is the three-dimensional equivalent to a morphing airfoil. On a morphing wing, an array of servo actuation points deflect the $\mathrm{RC}$ aircraft wing to the varying degrees required. These several actuation points allow production of the same lift magnitude on a wing while varying the yawing moment by changing where the drag forces originate. The principle of creating local induced-drag maxima was chosen as the method to control yaw.

For a morphing aft control-surface, the gradient along the trailing-edge must be sufficiently large to produce the requisite high gradients in lift. These high gradients in lift produce the maxima of the induced drag form needed for the

\footnotetext{
$¥$ https://github.com/benjaminmoulton/KINCSgeometry
} 
required yaw authority. The variable locations of the induced drag maxima along the wing produce the moments used to control the aircraft yaw. Thus, to produce high gradients in lift, the control surfaces must deflect dissimilarly along the wing. This is shown following in Figs. 11 and 14. Two control-surface types were examined as potential solutions to create large trailing-edge gradients along the wing.

\section{A. Discrete and Continuous Control Surfaces}

The first is a continuous control-surface in which servo motors control the deflection at multiple locations along the wing to maintain a continuous trailing-edge. An example can be seen in Fig. 11. One difficulty in this process, as will be examined later in this paper, comes from the need for a flexible skin that can shear deform between two servos, deflecting the neighboring sections in opposing directions.

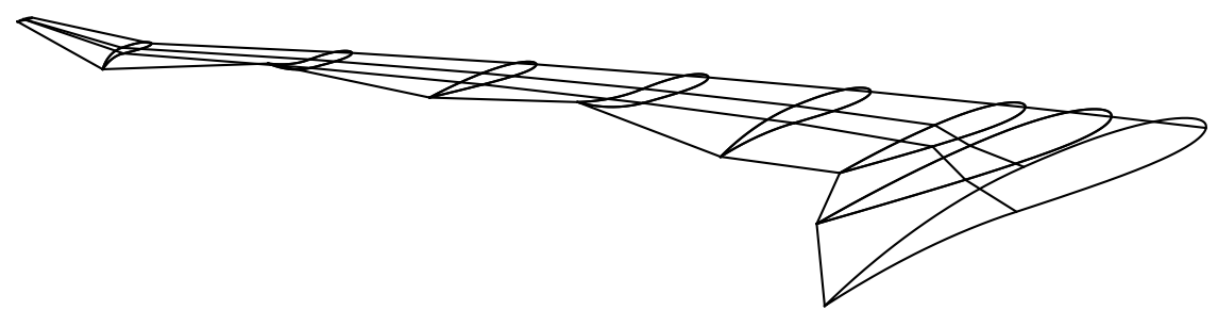

Fig. 11 Drawing of a continuous control-surface.

With this control-surface type, the layering of the TPU and PLA was examined to optimize the skin stiffness and flexibility. Two of the layering ratios are given following.

Span-wise layers - 1:1 ratio

With the slip joint geometry mentioned above, the layering of TPU to PLA was examined as 1:1. The top view of this layering is shown in Fig. 12

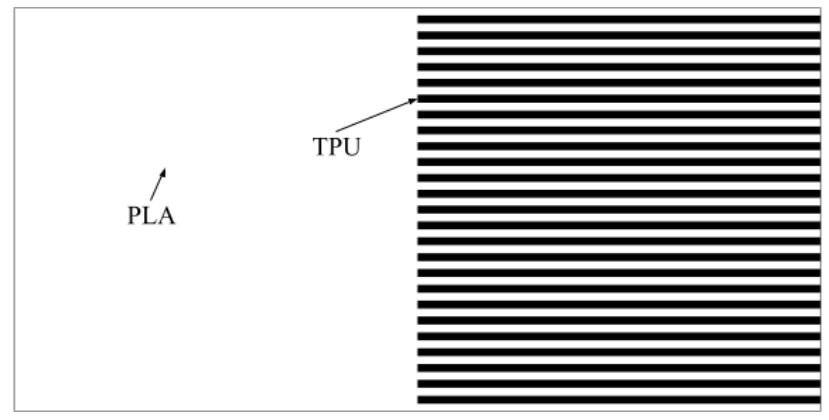

Fig. 12 Drawing of span-wise layers with equal TPU to PLA ratio.

This layering allowed for greater flexibility in the span-wise morphing. However, it was not sufficient for the trailing-edge gradients desired. This difficulty motivated the study of greater flex to stiff ratios.

Span-wise layers - 5:3 ratio

The final TPU to PLA layering was determined to be a ratio 5:3. This layering was used on the ARCS concept, and the top view can be seen below in Fig. 13 


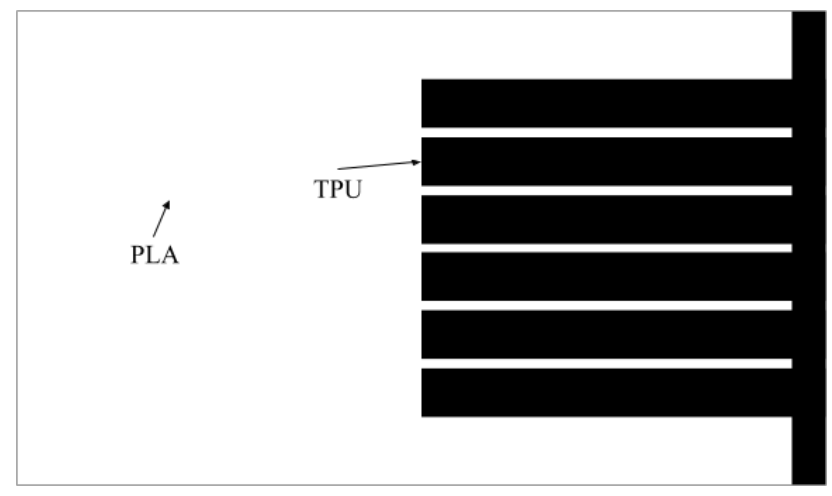

Fig. 13 Drawing of span-wise layers with greater TPU to PLA ratio.

Notably, the PLA sections are not equal as in the 1:1 ratio drawing in Fig. 12 The thicker PLA ribs are located where the wing will actuate, providing the stiffness requisite for deflection. The thinner ribs in between the two thicker PLA ribs provide the structural support between the ribs to prevent buckling. This layering provided the necessary flexibility and stiffness for the wing. For this reason, it was chosen for the ARCS design.

The second control-surface type uses discrete flaps in which distinct sections of the wing are unconnected along the morphing aft portion of the wing. An example can be seen below in Fig. 14. Each discrete control-surface may be deflected without influencing neighboring control-surfaces. This significantly increases the production of induced drag. Because the control surfaces are not interdependent, they can produce great discontinuities along the trailing edge. Thus, they create greater gradients in lift, and larger maxima in the induced drag form.

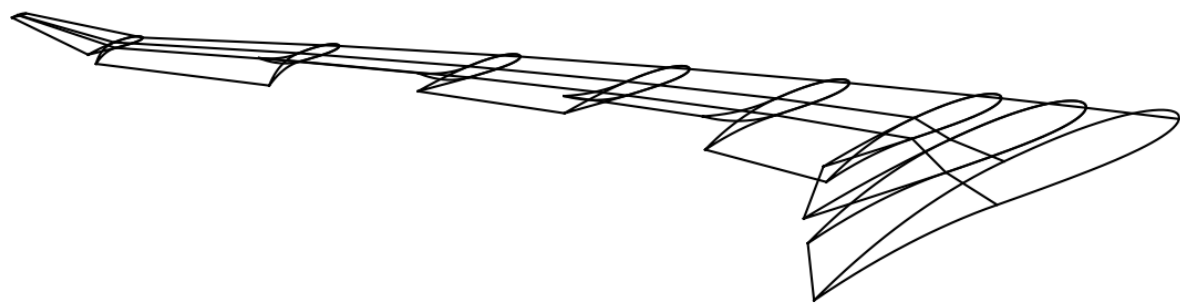

Fig. 14 Drawing of discrete control-surfaces.

Studies examining the yaw authority compared between these two control-surface types were performed by the USU AeroLab and will be published in the future. The findings of that research demonstrate that the yaw authority is greater for a wing with discrete control-surfaces compared to a wing with a continuous control-surface with the same number of actuators. This is caused by the greater gradients in lift associated with the discrete flaps. For this reason, the discrete control-surfaces were chosen for the final control-surface concept.

\section{Printing Characterization}

Having chosen FDM as the manufacturing method, an FDM printer with the desired characteristics was required for manufacturing. The desirable characteristics are given following. The slicer print settings and materials are tabulated below.

\section{A. FDM Printer Selection}

Following the decision to manufacture the wing using FDM, an FDM printer was selected. Potential FDM printers were examined based on the stipulations of a large build volume (greater than $300 \times 300 \times 300 \mathrm{~mm}^{3}$ ), dual extrusion capability, price less than $\$ 2,500$, and having direct-drive extruders. These requirements were deemed necessary characteristics to print the morphing wing mechanism. The printers examined are shown below in Table 1 
Table 1 Comparison of FDM printers.

\begin{tabular}{ccccc}
\hline \hline Printer & Dual Extruder & Build Volume, mm x mm x mm & Extruder Type & Price $\leq \mathbf{\$ 2 , 5 0 0}$ \\
Prusa i3 MK3 & - & $250 \times 210 \times 210$ & Direct-Drive & $\checkmark$ \\
Ultimaker S5 & $\checkmark$ & $330 \times 240 \times 300$ & Bowden & - \\
Creality3D CR-X & - & $300 \times 300 \times 400$ & Bowden & $\checkmark$ \\
Vivedino T-Rex 3.0 & $\checkmark$ & $400 \times 400 \times 700$ & Direct-Drive & $\checkmark$ \\
BCN3D Epsilon & $\checkmark$ & $420 \times 300 \times 400$ & Bowden & - \\
Raise3D Pro2 Plus & $\checkmark$ & $280 \times 305 \times 605$ & Bowden & - \\
\hline \hline
\end{tabular}

The Vivedino T-Rex 3.0 was chosen for this application. The dual extrusion capability allows the user to print dual-material prints, such as with PLA and TPU, as well as print symmetrical objects simultaneously. The larger build volume was desired due to the expected airframe size. With an expected span of $10 \mathrm{ft}$, the root chord was designed to be $33 \mathrm{in}$. With a minimum build plate size of $300 \times 300 \mathrm{~mm}$, the large root section can be split in two chord-wise and placed diagonally on the print bed. Direct-Drive extruders are preferable when printing with materials such as the TPU NinjaFlex ${ }^{\mathrm{TM}}$. Whereas Bowden extruders push the filament through an extended tube into the hot end, direct-drive extruders push the filament directly into the hot end, preventing most filament tangling and tensioning problems.

\section{B. Materials}

Originally all FDM printing was done using PLA. PLA is an inexpensive simple filament used in FDM. PLA was preferred to Acrylonitrile Butadiene Styrene (ABS) as PLA printing fumes are less toxic than ABS fumes. Also, PLA provided sufficient structural strength, as demonstrated by a previous FDM printed RC aircraft shown in Fig. 15

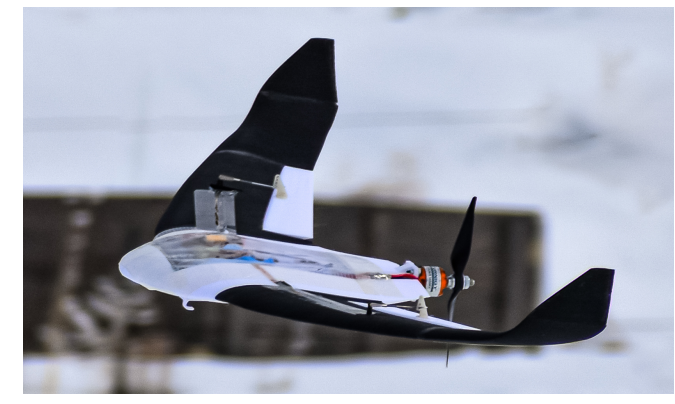

Fig. 15 Flight test of an FDM printed non-morphing RC aircraft.

PushPlastic ${ }^{\mathrm{TM} P L A}$ was used for the rigid sections of the ARCS geometry and the entire KINCS geometry. The PLA is used to add strength and flexibility to the printed structure. Notably, the PLA must be printed in thin sections to provide the flexibility. Using a skin thickness of two walls of $0.4 \mathrm{~mm}$ thickness were generally sufficient for the morphing upper and lower surfaces.

To provide the flexibility and stretchability required in the ARCS continuous-trailing-edge concept, TPU was examined as a potential secondary material. The TPU was incorporated with the PLA in later printing as a bi-material part. This was done in former prototypes using Flexfill ${ }^{\mathrm{T}}{ }_{5}$ printed in the aft portion of the wing. However, this flexible material did not provide the stretching required for the trailing edge gradient during a differential deflection. The TPU NinjaFlex ${ }^{\mathrm{TM}}$ was employed to provide this differential gradient. This extremely elastic TPU is difficult to print due to its flexible nature. However, it provides measurable elasticity for the trailing edge differential deflection. The rigid portion of the wing design was printed out of PLA. Later, PLA with TPU composite printing was incorporated in the skin on the morphing section to provide stiffness to the skin.

The filament colors were chosen based on their heating properties in outdoor conditions. Darker colors retained heat above the glass transition temperature, causing structural failure. Prototypes were colored to easily distinguish between the TPU and PLA. Eventually, models were printed out of all white materials as this color retains heat the least in higher

\footnotetext{
${ }^{\S}$ FlexFill ${ }^{\mathrm{TM}}$ is owned by Fillamentum, inc.
} 
outdoor temperatures and strong sunlight. However, PLA can also fail when kept in such conditions as a hot car, which was avoided.

The mono-material KINCS concept was designed due to the change in morphing design from continuous to discrete flaps. The removal of TPU from the print significantly decreased the time and complexity of the FDM printing process. The second extruder could then be used for symmetrical printing.

\section{Methods}

The following print settings and techniques resulted in the best print quality. It should be noted that the nozzles used to print the ARCS and KINCS geometries are $0.4 \mathrm{~mm}$ in diameter. Table 2 gives the settings used in the slicer Cura to recreate the ARCS and KINCS geometries. It should be noted that E stands for extruder, with E1 being the left extruder, and E2 being the right extruder. Unless otherwise stated using this nomenclature, the settings are shared between extruders.

Table 2 Print settings for the ARCS and KINCS geometries.

\begin{tabular}{ccc}
\hline \hline Setting & ARCS Geometry Value & KINCS Geometry Value \\
Layer Height, $\mathrm{mm}$ & 0.2 & 0.2 \\
Line Width, mm & 0.4 & 0.4 \\
Wall Thickness, mm & 0.8 & 0.8 \\
Z Seam Alignment & Random & Random \\
Infill Density & $3.0 \%$ & $3.0 \%$ \\
Build Plate Temperature, ${ }^{\circ} \mathrm{C}$ & 40 & 40 \\
E1 Material & PLA & PLA \\
E1 Print Temperature, ${ }^{\circ} \mathrm{C}$ & 210 & 225 \\
E1 Flow Rate & $100 \%$ & $100 \%$ \\
E1 Enable Retraction & True & True \\
E1 Retraction Distance, $\mathrm{mm}$ & 0.5 & 0.5 \\
E1 Retraction Speed, $\frac{m m}{s}$ & 30.0 & 30.0 \\
E1 Nozzle Switch Retraction Distance, $\mathrm{mm}$ & 10.0 & 10.0 \\
E1 Print Speed, $\frac{m m}{s}$ & 30.0 & 30.0 \\
E2 Material & TPU & PLA \\
E2 Print Temperature, ${ }^{\circ} \mathrm{C}$ & 235 & 225 \\
E2 Flow Rate & $120 \%$ & $100 \%$ \\
E2 Enable Retraction & True & True \\
E2 Retraction Distance, $\mathrm{mm}$ & 0.1 & 0.5 \\
E2 Retraction Speed, $\frac{m m}{s}$ & 10.0 & 30.0 \\
E2 Print Speed, $\frac{m m}{s}$ & 7.0 & 10.0 \\
Z Hop When Retracted & 20.0 & 30.0 \\
Z Hop Height, $m m$ & True & True \\
Build Plate Adhesion Type & 0.5 & 0.5 \\
Build Plate Adhesion Extruder & Brim & Brim \\
Brim Width, mm & Extruder 1 & Extruder 1 \\
E2 Nozzle Switch Retraction Distance, & 6 & 6 \\
\hline \hline
\end{tabular}

Due to the difficulty of printing TPU's, some lessons learned are given here. First, the NinjaFlex ${ }^{\mathrm{TM}}$ must be slowly inserted into the nozzle to prevent bunching up. Second, the flexible material extruder must have a print speed less than or equal to $30 \mathrm{~mm} / \mathrm{s}$. Third, the user should allow as little retraction as possible. Fourth, the user should print with a separate nozzle for TPU. Fifth, the user should clean the TPU nozzle frequently to prevent clogging, and print at $235^{\circ} \mathrm{C}$. 
For this unclogging the author used taulman3D Nylon 645 in cold pulls.

\section{Lessons From Prototyping}

Various examples are given of the successes and failures of the FDM manufacturing-method with each geometry. Significant testing results of the morphing airfoil and wing concepts as mentioned above are given below.

\section{A. Morphing Airfoil Lessons Learned}

Distinct lessons learned throughout this project as related to the morphing airfoil development are given in Table 3 Images of these models are shown in Fig. 16 Regarding the prototype nomenclature, "P" indicates a Prototype conceptual change, "I" a new Iteration of the Prototype, "M" a Modification of an Iteration, and "S" a Section. The first three divisions indicate the significance of a design change. A full concept change led to a new Prototype designation. Continued Iterations on this design further improved the morphing-wing model characteristics. If the Iteration was further studied with minor changes, the design was termed a Modification. Some few designs were split into Sections and designated as such. However, most Iterations were neither split into Sections nor underwent Modification. Thus, the "S" and "M" designations were dropped from the model name.

The reader should note that the trailing-edge gap geometry was given the Prototype designation P3. The remaining morphing-airfoil concept designations are as follows: the fish bone concept was given P4; the slip joint and semicircles concept was given P13; the ARCS concept was given P14; the KINCS concept was given P18.

Table 3 Significant prototyping lessons learned.

\begin{tabular}{|c|c|c|}
\hline Prototype & "Notable Success & Propelling Failure \\
\hline P3I1 & $3 \mathrm{D}$ printing works best span-wise & $\begin{array}{l}\text { Skin must be thin for actuation; need structure } \\
\text { in leading edge to prevent deformation }\end{array}$ \\
\hline P4I1 & Thin PLA can uniformly deflect sufficient & Spine too thick (must be $\leq 0.8 \mathrm{~mm}$ ) \\
\hline P4I9 & Flexible material prints well as an airfoil skin & $\begin{array}{l}\text { TPU does not stretch to allow a trailing edge } \\
\text { gradient }\end{array}$ \\
\hline P13I4 & Support for flexible material allows for tall prints & $\begin{array}{l}\text { Surfaces must be constrained to maintain airfoil- } \\
\text { thickness distribution }\end{array}$ \\
\hline P13I7 & $\begin{array}{l}\text { Adhesion between TPU and PLA is better in the } \\
\mathrm{X} \text { or } \mathrm{Y} \text { direction than in the } \mathrm{Z} \text { direction }\end{array}$ & $\begin{array}{l}\text { It would be easier to print the ribs with the } \\
\text { structure }\end{array}$ \\
\hline P14I1M1 & $\begin{array}{l}\text { ARCS allow for the thickness of the airfoil to } \\
\text { remain constant during deflection }\end{array}$ & $\begin{array}{l}\text { Need the morphing aft portion printed mostly } \\
\text { of flexible material to allow for trailing edge } \\
\text { gradient in differential deflection }\end{array}$ \\
\hline $\mathrm{P} 14 \mathrm{I} 4$ & $\begin{array}{l}\text { Flex ratio can be increased without significant } \\
\text { detriment to stiffness }\end{array}$ & Need to examine a mechanized concept \\
\hline P14I8 & Tongue control hole must be stiff & Need to test trailing edge gradient \\
\hline P14I9M5 & $\begin{array}{l}\text { Good ratio of TPU to PLA is } 5: 3 \text {, with } 7: 1 \\
\text { between ribs; sufficient stiffness for deflection } \\
\text { with PLA smaller ribs } 1 / 8 \text { in. wide and the } \\
\text { actuation ribs } 1 \text { in. wide }\end{array}$ & Need a thinner airfoil to improve deflection range \\
\hline P14I14 & Thinner airfoil leads to better deflection & Need 5 smaller ribs in between actuation ribs \\
\hline P14I17 & An avian-inspired airfoil deflects parabolically & Must examine a 3-servo mechanized concept \\
\hline P14I19 & $\begin{array}{l}\text { No trailing-edge flutter during a dynamic test; } \\
\text { Successful ARCS parabolic deflection }\end{array}$ & Improve surface quality of print \\
\hline P17I08M01 & KINCS design can create a parabolic deflection & Difficult laser-cut rib assembly \\
\hline P18I03M04 & KINCS can be 3D printed & 2 kinks provides too much aft stiffness \\
\hline P18I08M05 & A single kink works best for KINCS mechanism & Deflection is not sufficiently parabolic \\
\hline P18I10M01 & Successful KINCS parabolic deflection & - \\
\hline
\end{tabular}




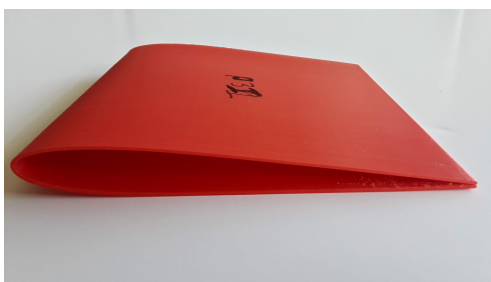

(a) P3I1

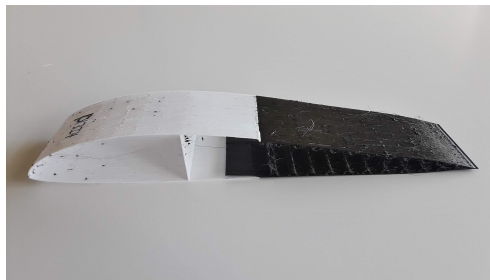

(d) P13I4

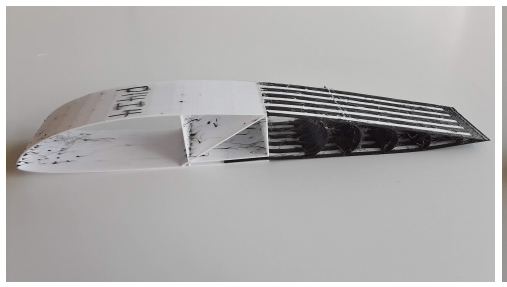

(g) P14I4

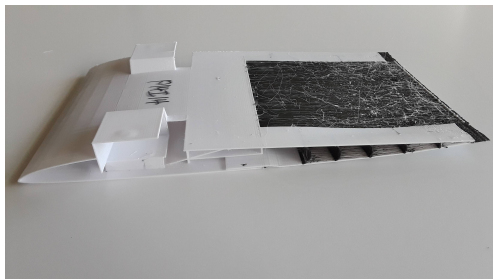

(j) P14I14

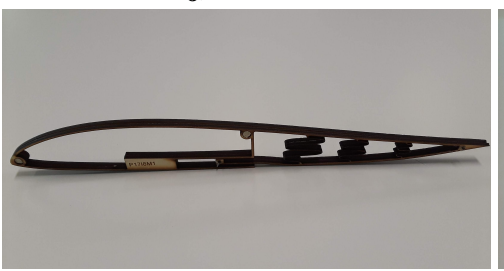

(m) P17I08M01

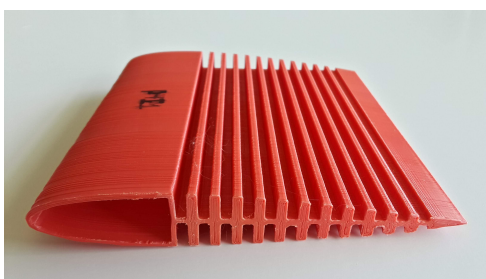

(b) P4I1

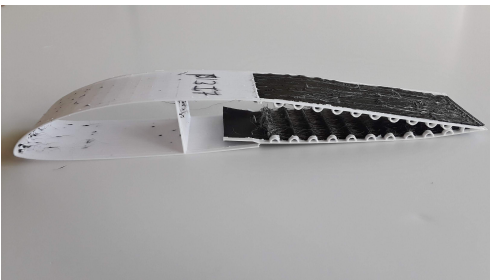

(e) P13I7

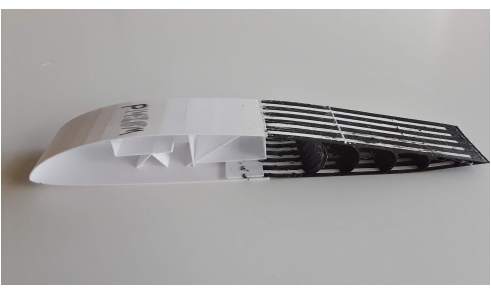

(h) P14I8

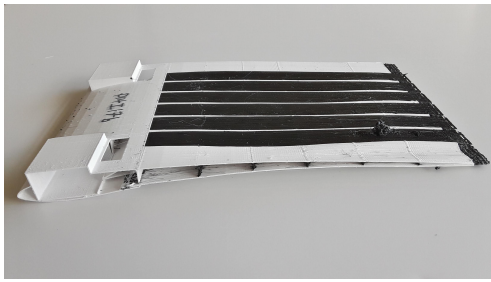

(k) P14I17

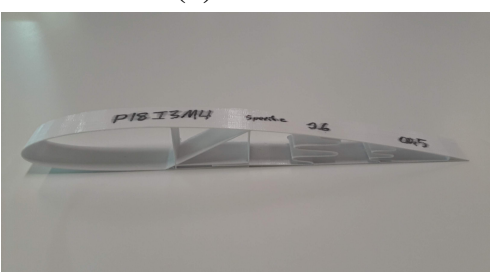

(n) P18I03M04

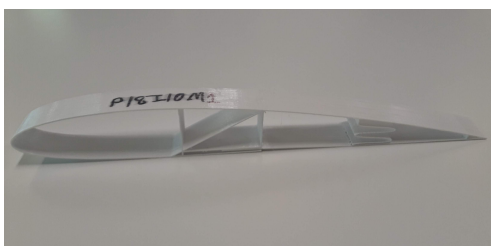

(p) P18I10M01

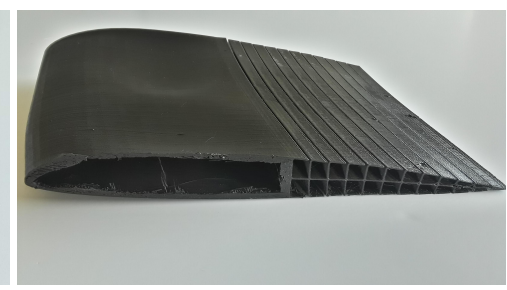

(c) P4I9

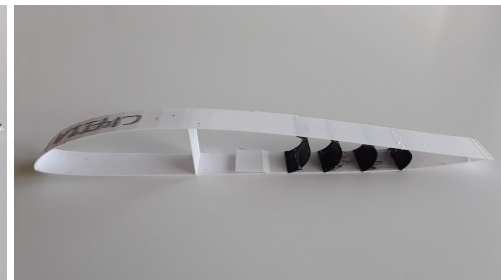

(f) P14I1M1

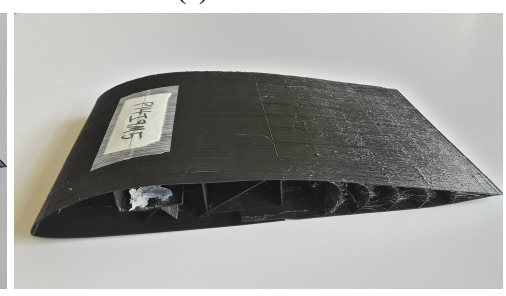

(i) P14I9M5

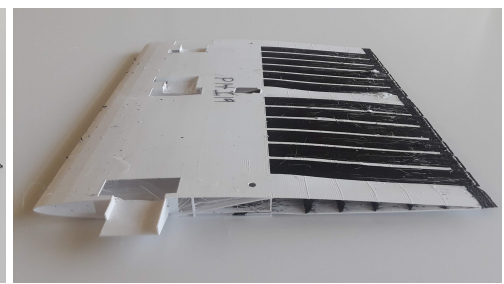

(l) P14I19

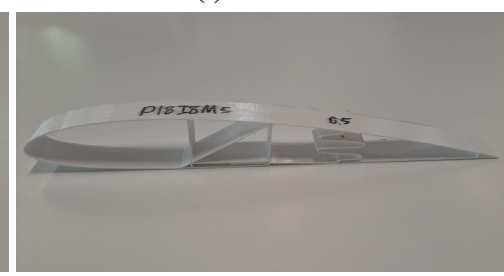

(o) P18I08M05

Fig. 16 Prototypes as described in table 3 .

Figure 17] shows the resultant parabolic deflection on the ARCS and KINCS concepts. 


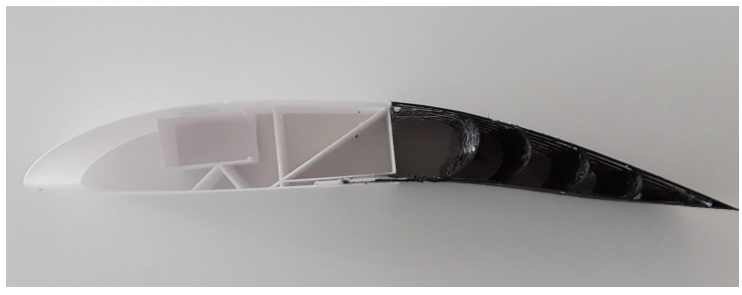

(a) P14I18M1 $+15^{\circ}$ deflection

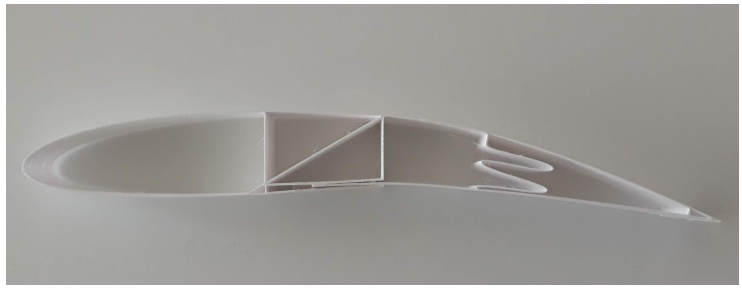

(c) P18I10M0 +15 ${ }^{\circ}$ deflection

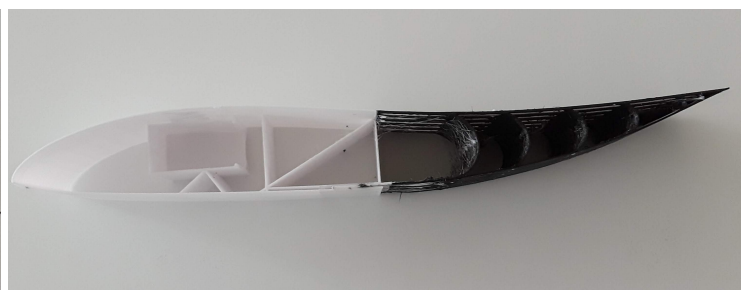

(b) P14I18M1 -15 ${ }^{\circ}$ deflection

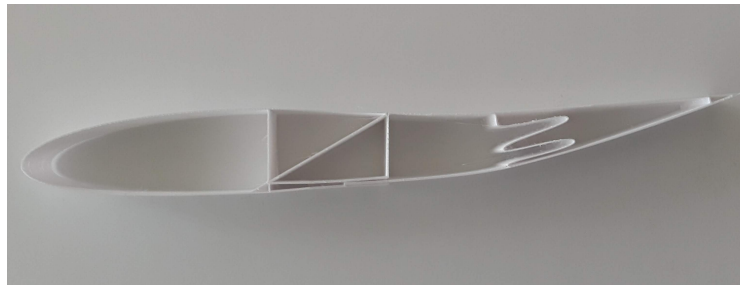

(d) P18I10M0 -15 ${ }^{\circ}$ deflection

Fig. 17 KINCS and ARCS geometry deflected parabolically, with $c_{f} / c=0.5$.

While both concepts demonstrate parabolic deflection, the KINCS concept was chosen for use with discrete flaps due to it being manufacturable from a single material.

\section{B. Morphing Wing Lessons Learned}

The KINCS and ARCS designs both had similar difficulties with taper and sweep geometric characteristics. In a tapered section, as the tongue moves forward within the slip joint (deflecting the flap downward), the taper causes the tongue to slide transversely. With taper, the tongue tip will slide toward the section tip, and the tongue root will slide toward the section root. In a swept section, as the tongue moves forward within the slip joint, the sweep causes the tongue to slide transversely, but in the opposite direction of the taper (assuming traditional taper and sweep). With sweep, the tongue tip will slide toward the section root, and the tongue root will slide toward the section tip.

We have noted taper to have a greater effect on this transverse sliding than sweep. This was noted on the morphing-wing discrete-flap segments of the Horizon aircraft [18]. The Horizon aircraft has significant taper with a root chord of $2.75 \mathrm{ft}$ and a tip chord of $0.917 \mathrm{ft}$, and sweep which is linearly changing from $0^{\circ}$ at the root and $45^{\circ}$ at the tip [18]. Due to these opposing effects, the sliding problems were nearly negligible on the Horizon aircraft.

\section{Differential Deflection}

This research as described in Table 3 and shown in Fig. 16 began as a study to manufacture a continuous trailing-edge morphing wing. Examples of this type of deflection is shown in Fig. 18

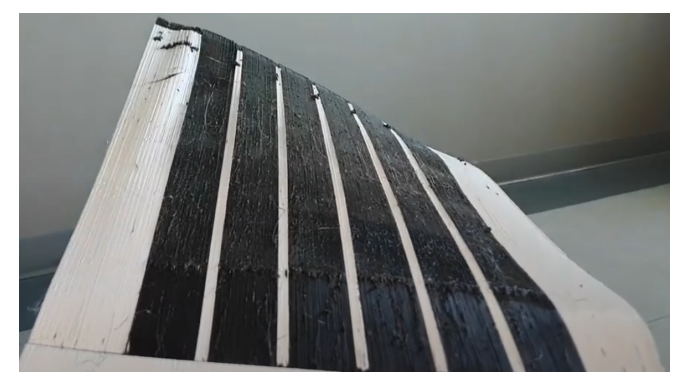

(a) P14I17 - two actuators

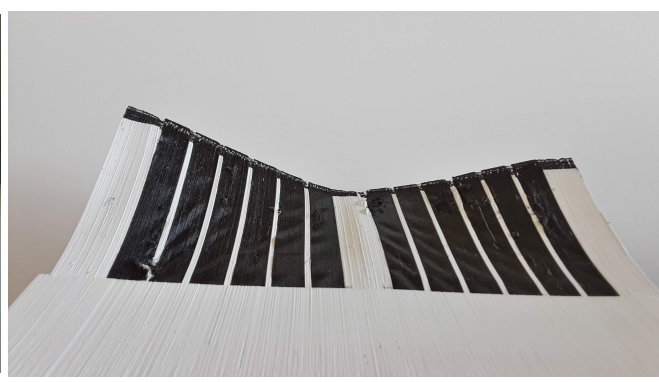

(b) P14I19 - three actuators

Fig. 18 Differential deflection on the ARCS geometry.

Significant problems impeded further study of this design, as shown in the buckling of the flexible skin surface seen above. It was at this point in the design process that the decision was made to construct the wing using discrete flaps, 
eliminating the need for a flexible skin. Further study is recommended into the use of the ARCS mechanism for 3D printed morphing-wing aircraft.

\section{Discrete Deflection}

With the determination to use discrete flaps, the KINCS mechanism was chosen for the final design. As it is a mono-material design, it was much simpler and faster to print. This control-surface type can be seen on a model of Horizon in Fig. 19
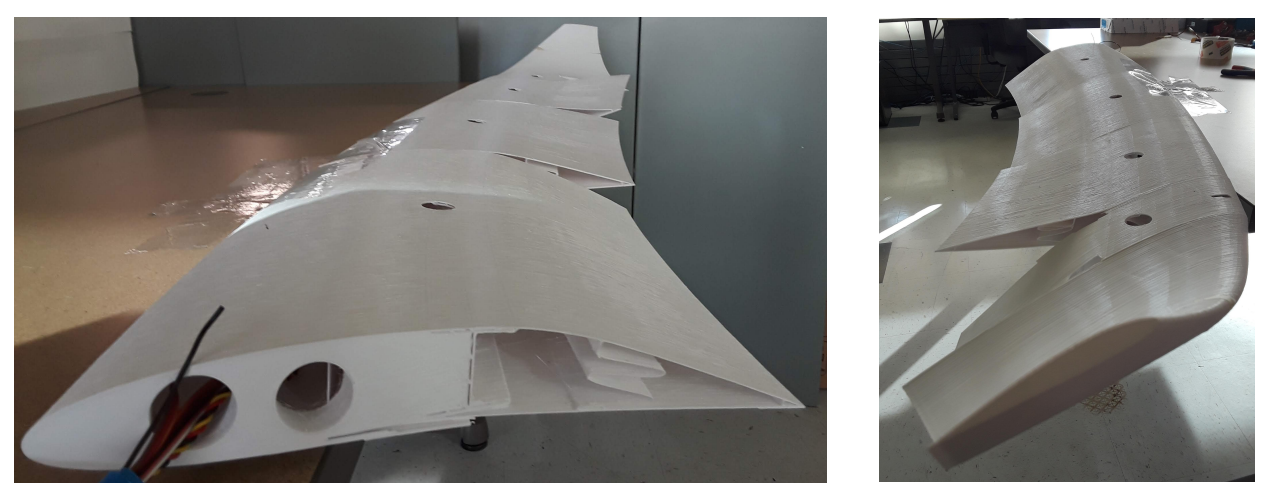

Fig. 19 Discrete deflection on Horizon wing-segment (P18I17S04 - P18I17S07).

\section{Final Design}

The KINCS mechanism was chosen for the final design. A flying-wing design has been outlined using the KINCS morphing geometry [18]. The final KINCS morphing airfoil is shown in Fig. 20. Some geometric changes were made for the final flying-wing design. These changes include an I beam for wing structural rigidity located near the hinge point, and custom infill geometry in the leading-edge portion to allow for cables through the wing. In blue on the figure is the optimal placement for the servo mechanism, a Hitech ${ }^{\mathrm{TM}} \mathrm{HS}-5245 \mathrm{MG}$ digital servo.

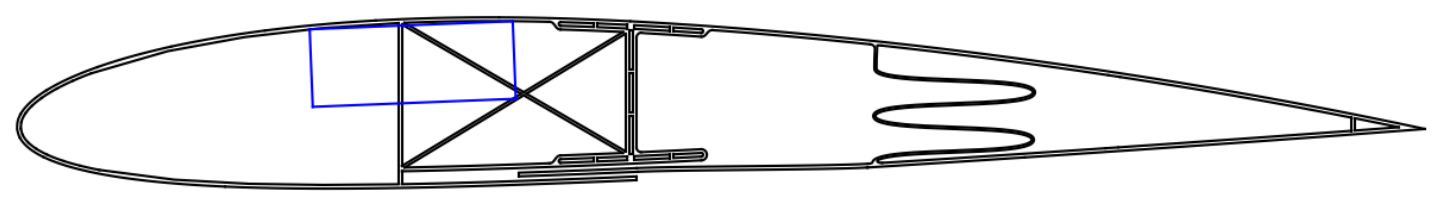

Fig. 20 Final KINCS geometry in a NACA 2412 airfoil, with $c_{f} / c=0.66$.

The discrete control-surfaces were cosine clustered span-wise to improve Horizon's yaw control. The Computer Aided Design (CAD) model can be seen in Fig. 21. The reader can retrieve the CAD models used to manufacture this aircraft 国

\footnotetext{
IIhttps://www.thingiverse.com/thing:4672874
} 

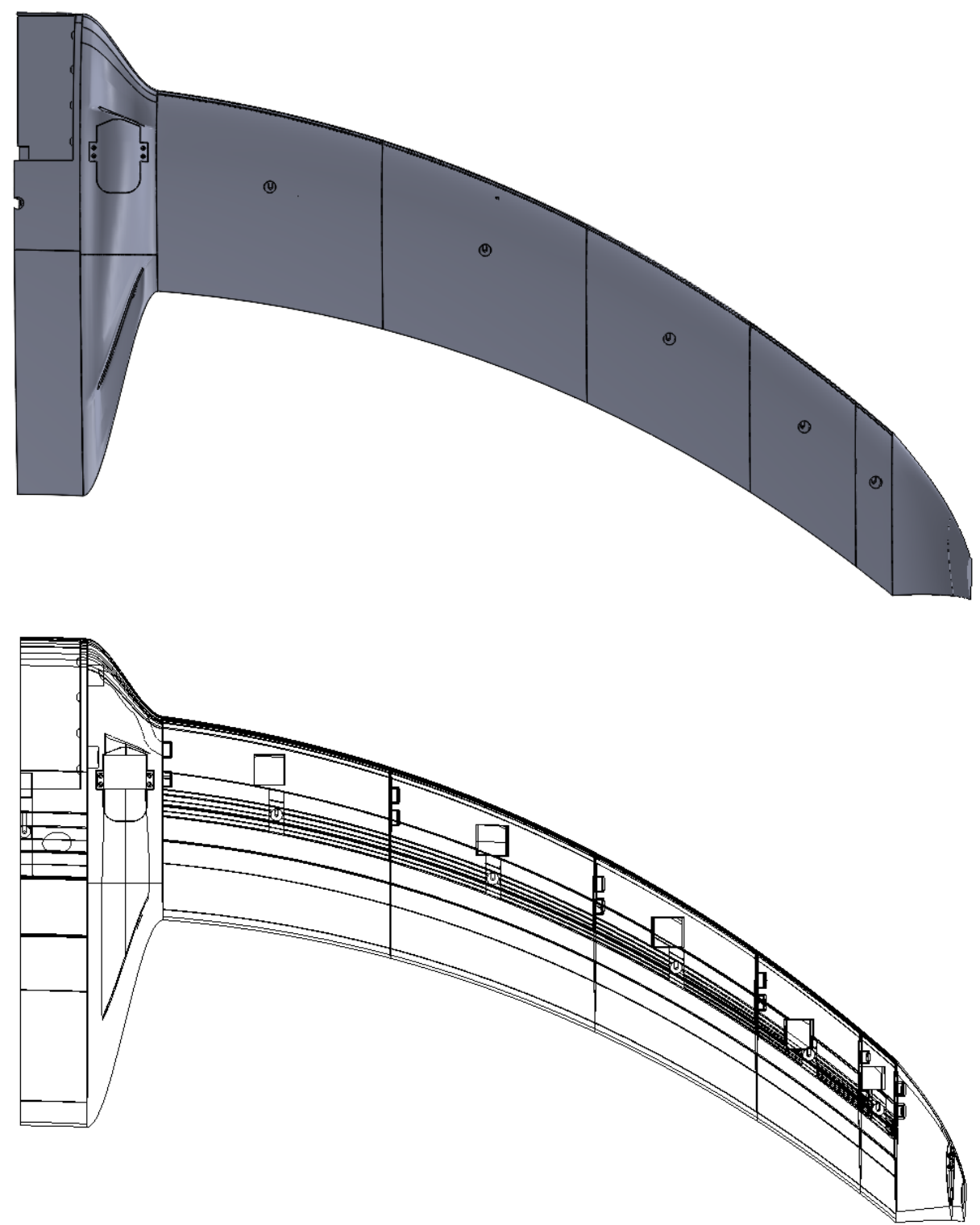

Fig. 21 Cosine clustered discrete flaps on Horizon aircraft CAD model.

The servo locations can be seen on the lower figure in Fig. 21. The servos were placed spatially in the middle of each discrete section. The Sections on Horizon are designated numerically as described above, with 00 for the root section, and 07 for the tip section. It should be noted that Sections 01 and 07 are non-morphing Sections. Section 01 is non-morphing due to the placement of the ducted fans to propel Horizon. Section 07 is the non-morphing wing tip section. The deflections for the outboard morphing sections are given in Fig. 22 


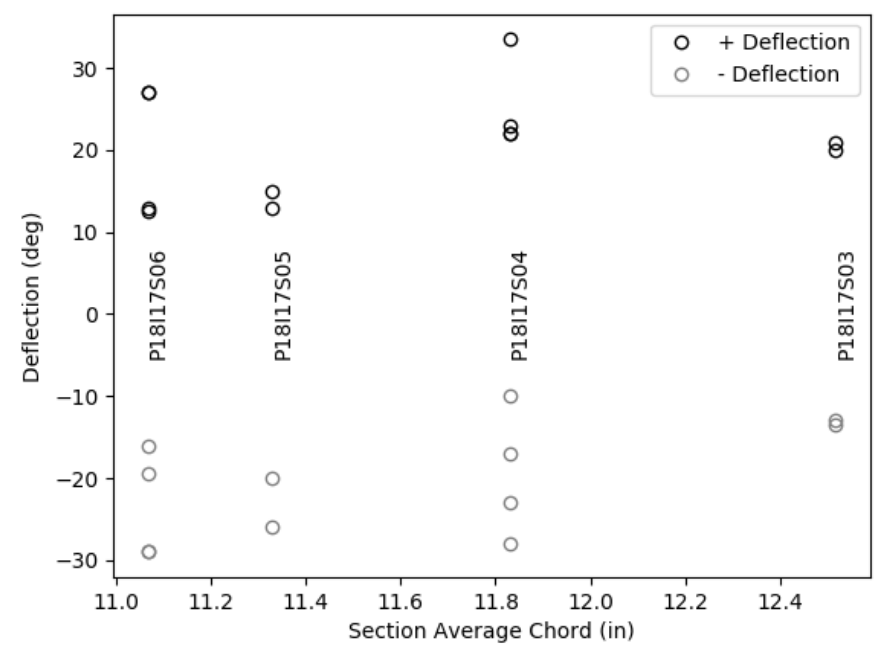

Fig. 22 Deflection for the outboard Sections on Horizon.

The multiple data points for each Section indicate the various tests performed. The morphing sections were noted to bind when deflecting near each other. This was mitigated by removing a slice from the tip portion of each Section of 1/4 in. at the trailing edge linearly up to no removal at the hinge point. This change resulted in the high deflections shown above. This demonstrates the KINCS mechanism capability of deflecting $\pm 25^{\circ}$. Further study is recommended into the use of the KINCS mechanism for 3D printed morphing-wing aircraft.

\section{Conclusion}

Morphing aircraft have the potential to control aerodynamic forces more efficiently than traditional aircraft. Recent studies of morphing flight have demonstrated the viability and preferability of morphing flight. Several of these recent studies have examined FDM manufactured wings. A fully 3D printable wing which requires little to no post-processing allows for significant improvement in iterative design. The ARCS design can be used as a fully 3D printable design. This design actuates with significant deflection, sufficient to control in-flight forces as a continuous control-surface. The KINCS design can also be used as a fully 3D printable design, and is recommended for use with discrete control-surfaces. This mechanism is capable of producing the necessary deflection for a yaw-controllable flying-wing aircraft.

\section{Acknowledgments}

This work was funded by the U.S. Office of Naval Research Sea-Based Aviation program (Grant No. N00014-18-12502) with Brian Holm-Hansen as the program officer.

\section{References}

[1] Joo, J. J., Marks, C. R., Zientarski, L., and Culler, A. J., "Variable camber compliant wing-design," 23rd AIAA/AHS adaptive structures conference, 2015, p. 1050.

[2] Nguyen, N., and Urnes, J., "Aeroelastic modeling of elastically shaped aircraft concept via wing shaping control for drag reduction," AIAA Atmospheric Flight Mechanics Conference, 2012, p. 4642.

[3] Kota, S., Hetrick, J. A., Osborn, R., Paul, D., Pendleton, E., Flick, P., and Tilmann, C., "Design and application of compliant mechanisms for morphing aircraft structures," Smart structures and materials 2003: industrial and commercial applications of smart structures technologies, Vol. 5054, International Society for Optics and Photonics, 2003, pp. 24-33.

[4] Molinari, G., Quack, M., Arrieta, A. F., Morari, M., and Ermanni, P., "Design, realization and structural testing of a compliant adaptable wing," Smart Materials and Structures, Vol. 24, No. 10, 2015, p. 105027. 
[5] Yokozeki, T., Sugiura, A., and Hirano, Y., "Development and wind tunnel test of variable camber morphing wing," 22nd AIAA/ASME/AHS adaptive structures conference, 2014, p. 1261.

[6] Rauleder, J., van der Wall, B. G., Abdelmoula, A., Komp, D., Kumar, S., Ondra, V., Titurus, B., and Woods, B. K., "Aerodynamic performance of morphing blades and rotor systems," AHS International 74th Annual Forum \& Technology Display, 2018, p. 1.

[7] Woods, B. K., and Friswell, M. I., "Structural characterization of the fish bone active camber morphing airfoil," 22nd AIAA/ASME/AHS Adaptive Structures Conference, 2014, p. 1122.

[8] Pankonien, A., and Inman, D. J., "Experimental testing of spanwise morphing trailing edge concept," Active and Passive Smart Structures and Integrated Systems 2013, Vol. 8688, International Society for Optics and Photonics, 2013, p. 868815.

[9] Pankonien, A. M., and Reich, G. W., “Multi-Material Printed Wind-Tunnel Flutter Model,” AIAA Journal, 2018 , pp. $793-807$.

[10] Ricci, S., De Gaspari, A., and Riccobene, L., "Design, Manufacturing and Wind Tunnel Test of a Morphing Wing Based on Compliant Structures,” 24th AIAA/AHS Adaptive Structures Conference, 2016, p. 1316.

[11] Jakubinek, M., Roy, S., Palardy-Sim, M., Ashrafi, B., Shadmehri, F., Renaud, G., Barnes, M., Martinez-Rubi, Y., Rahmat, M., Simard, B., et al., "Stretchable structure for a benchtop-scale morphed leading edge demonstration," AIAA SciTech 2019 forum, 2019, p. 1857.

[12] Leal, P. B., White, T., Goecks, V. G., Valasek, J., and Hartl, D. J., "Experimental and computational assessment of a shape memory alloy based morphing wing incorporating linear and non-linear control," 2018 AIAA/AHS Adaptive Structures Conference, 2018, p. 0800.

[13] Hunsaker, D. F., Reid, J. T., Moorthamers, B., and Joo, J. J., "Geometry and Aerodynamic Performance of Parabolic Trailing-Edge Flaps,” 2018 AIAA Aerospace Sciences Meeting, 2018, p. 1278.

[14] Howell, L. L., Compliant Mechanisms, John Wiley \& Sons, 2001.

[15] Monner, H. P., "Realization of an optimized wing camber by using formvariable flap structures," Aerospace Science and Technology, Vol. 5, No. 7, 2001, pp. 445-455.

[16] Phillips, W. F., "Pitch Stability of a Cambered Wing," Mechanics of Flight, John Wiley and Sons, Inc., 2010, Chap. 4, $2^{\text {nd }}$ ed., pp. 381-384.

[17] Ananda, G. K., and Selig, M. S., "Design of bird-like airfoils,” 2018 AIAA Aerospace Sciences Meeting, 2018 , p. 0310.

[18] Snow, S. A., and Hunsaker, D. F., "Design and Performance of a 3D-Printed Morphing Aircraft," AIAA SciTech 2021 forum, 2021, p. 1060. 